\title{
Resistance to Fluopyram, Fluxapyroxad, and Penthiopyrad in Botrytis cinerea from Strawberry
}

Achour Amiri, Stacy M. Heath, and Natalia A. Peres, University of Florida, Gulf Coast Research and Education Center, Wimauma 33598

\begin{abstract}
Amiri, A., Heath, S. M., and Peres, N. A. 2014. Resistance to fluopyram, fluxapyroxad, and penthiopyrad in Botrytis cinerea from strawberry. Plant Dis. 98:532-539.

Succinate dehydrogenase inhibitors (SDHIs) constitute a mainstay in management of gray mold caused by Botrytis cinerea in strawberry and several other crops. In this study, we investigated the risks of resistance development to three newer SDHIs (i.e., fluopyram, fluxapyroxad, and penthiopyrad) and their cross-resistance with the previously registered boscalid. We investigated the mutations in the SdhB subunit and evaluated their impact on microbial fitness in field populations of B. cinerea. Amino acid substitutions associated with resistance to SDHIs were detected at three codons of the $\mathrm{SdhB}$ subunit $\left(\mathrm{B}^{\mathrm{H} 272 \mathrm{R} / \mathrm{Y} / \mathrm{L}}\right.$, $\mathrm{B}^{\mathrm{P} 225 \mathrm{~F}}$, and $\mathrm{B}^{\mathrm{N} 230 \mathrm{I}}$ ) in the succinate dehydrogenase gene of field isolates from Florida. The $\mathrm{B}^{\mathrm{H} 272 \mathrm{R}}, \mathrm{B}^{\mathrm{H} 272 \mathrm{Y}}, \mathrm{B}^{\mathrm{H} 272 \mathrm{~L}}, \mathrm{~B}^{\mathrm{P} 225 \mathrm{~F}}$, and $\mathrm{B}^{\mathrm{N} 230 \mathrm{I}}$ mutations were detected at frequencies of 51.5, 28.0, 0.5, 2.5, and 4\%, respectively. Strong cross-resistance patterns were evident between boscalid and fluxapyroxad and penthiopyrad but not with fluopyram, except in

$\mathrm{B}^{\mathrm{H} 272 \mathrm{~L}}, \mathrm{~B}^{\mathrm{P} 225 \mathrm{~F}}$, and $\mathrm{B}^{\mathrm{N} 230 \mathrm{I}}$ mutants. All five mutations conferred moderate to very high resistance to boscalid whereas the $\mathrm{B}^{\mathrm{H} 272 \mathrm{Y}}$ conferred resistance to fluxapyroxad and penthiopyrad. The $\mathrm{B}^{\mathrm{H} 272 \mathrm{~L}}, \mathrm{~B}^{\mathrm{N} 230 \mathrm{I}}$, and $\mathrm{B}^{\mathrm{P} 225 \mathrm{~F}}$ mutations conferred high resistance to all four SDHIs tested. Resistance monitoring following the first use of penthiopyrad in strawberry fields in Florida in 2013 suggests potential for quick selection for highly resistant populations and warrants careful use of the newer SDHIs. No evidence of major fitness costs due to the mutations in the SdhB subunit was found, which indicates the potential ability of the mutants to survive and compete with wild-type isolates. Our study suggests high risks for rapid widespread occurrence of $B$. cinerea populations resistant to the novel SDHIs unless appropriate rotation strategies are implemented immediately upon registration.
\end{abstract}

The succinate dehydrogenase (SDH) complex is the target for several fungicides frequently used in agriculture. At least 16 commercial fungicides from the succinate dehydrogenase inhibitor (SDHI) group are currently available for the control of several pathogenic fungi (18). The SDHIs disrupt the energy cycle by binding near the ubiquinone reduction site of SDH and constitute a major component for the management of various diseases worldwide, including gray mold, caused by Botryotinia fuckeliana (anamorph: Botrytis cinerea) on strawberry and on more than 200 other crops (46).

The first SDHIs, carboxin, an oxathiin-carboxamide, and flutolanil, a phenyl-benzamide, were introduced to the market in 1966 and 1986, respectively, and were only active against basidiomycete fungi. A substitution of the oxathiin ring by a pyridine moiety and the introduction of a phenyl group at the anilide ring resulted in boscalid, which has activity against ascomycete as well as against the basidiomycete fungi (39). The SDHIs are classified as medium to high risk for resistance development because of their single-site mode of action. Resistance to carboxin, flutolanil, and boscalid was reported shortly after their introduction to the market and has been linked to point mutations in one of the subunits $(\mathrm{B}, \mathrm{C}$, or $\mathrm{D})$ of the SDH complex $(6,9,19,20,24,29,38)$. Resistance to boscalid in $B$. cinerea field isolates from apple, strawberry, and grape was associated with two main mutations (H272R or -Y) at codon 272 near the highly conserved (3Fe-4S) iron-sulfur cluster of the SdhB subunit $(11,12,26,43,48)$. Additional but less frequent mutations

Corresponding author: A. Amiri, E-mail aamiri@ufl.edu

* The $\boldsymbol{e}$-Xtra logo stands for "electronic extra" and indicates that one supplementary table and two supplementary figures are available online.

Accepted for publication 30 October 2013.

http://dx.doi.org/10.1094/PDIS-07-13-0753-RE

(c) 2014 The American Phytopathological Society have also been reported at codons 225,230 , and 272 in the $\mathrm{SdhB}$ of field isolates of $B$. cinerea and in lab mutants of Mycosphaerella graminicola $(26,36,43,48)$. The different aforementioned mutations in the SdhB subunit were linked to different resistant phenotypes. The less frequent mutations (i.e., the histidine and proline substitutions by a leucine $[\mathrm{H} 272 \mathrm{~L}]$ and a phenylalanine $[\mathrm{P} 225 \mathrm{~F}]$ at codons 272 and 225, respectively) seem to confer higher levels of resistance to boscalid in vitro (43). However, the remaining mutations have been reported to cause low, medium, and high levels of resistance in $B$. cinerea isolates from apple and grape $(26,48)$. Additionally, mutations in the $\mathrm{SdhC}$ and $\mathrm{SdhD}$ subunits were identified to be independently responsible for resistance to boscalid in other pathogenic fungi $(7,24,37)$. In $B$. cinerea, mutations conferring resistance to boscalid were reported only in the $\mathrm{SdhD}$, where a substitution of histidine by an arginine at codon 132 (H132R) conferred resistance to boscalid (26).

Seven new SDHIs have been recently developed and are expected to be registered to control a wide range of plant-pathogenic fungi in fruit, vegetable, and field crops. Penthiopyrad, fluxapyroxad, isopyrazam, penflufen, bixafen, and sedaxane belong to the pyrazole-carboxamide group, whereas fluopyram is from the pyridinyl-ethyl-benzamide group. Penthiopyrad, first developed in 2008 and registered in 2012 in Florida, is highly effective against numerous fungal plant pathogens $(10,13,15,35,47)$. Fluxapyroxad and fluopyram are expected to be registered for the control of $B$. cinerea and several other fungi on different fruit and vegetable crops in the near future. Preliminary reports indicate high efficacy of these two fungicides against several fungi $(2,8,17,23)$. Although all these fungicides belong to the same cross-resistance group, structural differences between the SDHIs may suggest differences in binding properties to the target enzyme.

In our recent study, about $80 \%$ of $B$. cinerea isolates from strawberry fields in Florida were resistant to boscalid $(3,4)$. Thus, it becomes crucial to evaluate the efficacy of the novel SDHIs and the risks for cross-resistance with boscalid before their use in commercial fields. Therefore, we initiated this study to (i) establish the in vitro and in vivo baseline sensitivity of $B$. cinerea from straw- 
berry to fluopyram, fluxapyroxad, and penthiopyrad; (ii) characterize the cross-resistance patterns between the novel SDHIs and boscalid; (iii) investigate the molecular mechanisms of resistance in B. cinerea to the newer SDHIs; and (iv) evaluate the impact of different mutations found in the $\mathrm{SdhB}$ on the fitness of $B$. cinerea.

\section{Materials and Methods}

Fungal isolates. In this study, $654 \mathrm{~B}$. cinerea isolates collected between 2005 and 2013 from 14 commercial annual strawberry fields in Florida were used. One field was located in Citrus County, one in Polk County, and the remaining fields were located in Hillsborough County, home of $90 \%$ of the strawberry production in Florida. In all, 34 isolates were collected between 2005 and 2010 whereas 58, 236, and 326 isolates were collected in 2011, 2012, and 2013, respectively. These fields have been regularly sprayed with a mixture of boscalid and pyraclostrobin (Pristine; BASF) since 2004 whereas penthiopyrad was used for the first time in some locations in 2013. Four of these locations (i.e., FS, PC, FY, and SS) that were regularly monitored since 2010 for resistance to boscalid and where penthiopyrad was used in 2013 were monitored to evaluate the progress of resistance to penthiopyrad. Penthiopyrad (Fontelis; DuPont Crop Protection) was used twice (17 January and 25 February), twice (4 January and 7 February), once (4 January), and once (7 February) at FS, FY, PC, and SS, respectively. For all isolates, symptomatic fruit were collected from the fields at the end of the strawberry season (February), after most of fungicide applications had been made. Isolates were single-spored and conidial suspensions were prepared prior to each experiment as described previously (3).

Fungicide sensitivity. To test whether the sensitivity to the new SDHIs is affected by the nature of the medium used, the sensitivity to fluopyram, fluxapyroxad, and penthiopyrad was pre-evaluated on five different media: potato dextrose agar (PDA), minimal medium (MM) (33), Czapeck agar (CzA) (28), and yeast bacto acetate agar (YBA) $(31,40)$ (and 2\% water agar [WA] for germination only). The sensitivity of 10 isolates was evaluated on each medium using mycelial growth and germination inhibition assays, as explained previously (3). Preliminary data showed higher values for the effective concentration necessary to inhibit spore germination or mycelial growth by $50 \%\left(\mathrm{EC}_{50}\right)$ of isolates on $\mathrm{CzA}$ compared with PDA and $\mathrm{MM}$, on which equal $\mathrm{EC}_{50}$ values were observed, whereas little growth was observed after $48 \mathrm{~h}$ on YBA (data not shown). Although lower $\mathrm{EC}_{50}$ values were observed in a 40 -isolatesubsample tested using both germination inhibition on WA and mycelial growth on PDA, strong correlations were observed between the two assays (data not shown). Ultimately, PDA, which was used previously to test for sensitivity to the new SDHIs in other fungi (8), was chosen for sensitivity tests in $B$. cinerea.

The sensitivity of 200 isolates (i.e. 34,58 , and 108 isolates collected in 2010, 2011, and 2012, respectively) to formulated fluopyram SC 500 (Luna Privilege; Bayer CropScience), penthiopyrad (Fontelis), fluxapyroxad (Xemium; BASF), and boscalid (Endura; $\mathrm{BASF}$ ) was evaluated by determining the $\mathrm{EC}_{50}$. The sensitivity of the remaining isolates was characterized using discriminatory doses, as explained below. The $\mathrm{EC}_{50}$ values were determined using the spiral gradient dilution (SGD) method, as described previously $(14,45)$, except that agar strips were used instead of cellophane strips (3). Several concentrations over multiple ranges determined by the spiral gradient endpoint (SGE) software (Spiral System, Autoplate 4000 model; Spiral Biotech) were first tested to select the most appropriate concentration for each fungicide. Initially, fluopyram, fluxapyroxad, and penthiopyrad were applied to $15-\mathrm{cm}$ plates, as described below, at final concentrations of 3,703, 3,652, and $3,578 \mu \mathrm{g} / \mathrm{ml}$, respectively. The respective $\mathrm{EC}_{50}$ value ranges starting from the edge toward the center of the gradient dilution were $<0.14$ to $28.64,<0.14$ to 27.89 , and $<0.14$ to $28.34 \mu \mathrm{g} / \mathrm{ml}$. Isolates showing $\mathrm{EC}_{50}$ values higher than those determined by the aforementioned ranges were tested for fluopyram and fluxapyroxad using concentrations of 18,516 and $18,265 \mu \mathrm{g} / \mathrm{ml}$, respectively, allowing ranges of 0.7 to $>143$ and 0.7 to $>141 \mu \mathrm{g} / \mathrm{ml}$, respectively. The sensitivity to boscalid was evaluated in a conidial germination assay on WA, as described previously $(1,3,25)$. All tests were conducted at $22^{\circ} \mathrm{C}$ and incubation time was 24 and $48 \mathrm{~h}$ for mycelial and conidial tests, respectively.

The sensitivity of the 454 remaining isolates collected in 2012 and 2013 was determined based on conidial germination inhibition using discriminatory doses of 5 and $500 \mu \mathrm{g} / \mathrm{ml}$ for boscalid to screen for moderate and high resistance, respectively. The $5-\mu \mathrm{g} / \mathrm{ml}$ dose discriminated resistant from sensitive isolates whereas boscalid at $500 \mu \mathrm{g} / \mathrm{ml}$ was used to discriminate very highly resistant from highly resistant isolates of $B$. cinerea $(3,48)$. The sensitivity to fluopyram, fluxapyroxad, and penthiopyrad was assessed based on mycelial growth inhibition on PDA amended with each fungicide at $50 \mu \mathrm{g} / \mathrm{ml}$. Isolates that grew $50 \%$ or more relative to a PDA control were considered resistant. Fruit tests were conducted as explained below to verify that isolates characterized as resistant in vitro were not controlled on fruit sprayed preventively with the three new SDHIs.

Isolates were grouped into five different sensitivity phenotypes for boscalid-highly sensitive (HS), sensitive (S), with reduced sensitivity (RS), moderately resistant (MR), and highly resistant (HR) - based on resistance factors (RFs) calculated from $\mathrm{EC}_{50}$ values $(3,48)$. HS and $\mathrm{S}$ isolates for boscalid were reported previously (12). Sensitivity phenotypes for the newer SDHIs were established in comparison with boscalid.

Characterization of mutations linked with resistance to the SDHIs in field isolates. In total, 200 isolates were cultured for 4 to 5 days in potato dextrose broth (PDB) and mycelium was collected by centrifugation, washed with sterile distilled water, and stored at $-20^{\circ} \mathrm{C}$. Genomic DNA was extracted using the FastDNA kit (MP Biomedicals) according to the manufacturer's protocol. All 200 isolates were characterized as B. cinerea sensu stricto based on diversity in the hch gene (16). An 850-bp fragment of the ironsulfur protein $\mathrm{SdhB}$ subunit was amplified using the primer sets shown in Table 1 from six sensitive isolates; eight isolates resistant to boscalid only; eight isolates resistant to boscalid, fluxapyroxad and penthiopyrad; and eight isolates resistant to all four SDHIs Polymerase chain reaction (PCR) was performed in a $25-\mu$ l volume containing $2 \mu \mathrm{l}$ of $10 \times$ buffer (New England Biolabs), $1.5 \mathrm{mM}$ $\mathrm{MgCl}_{2}, 2 \mathrm{mM}$ dNTPS (Promega Corp.), $0.2 \mu \mathrm{M}$ each primer, and 0.5 unit of Taq polymerase (New England Biolabs). PCR reactions were performed in a PTC-200 thermal cycler (MJ Research) using the following parameters: an initial denaturation at $95^{\circ} \mathrm{C}$ for $3 \mathrm{~min}$; 35 cycles of $94^{\circ} \mathrm{C}$ for $40 \mathrm{~s}, 55^{\circ} \mathrm{C}$ for $40 \mathrm{~s}$, and $72^{\circ} \mathrm{C}$ for $1 \mathrm{~min}$; and a final extension at $72^{\circ} \mathrm{C}$ for $5 \mathrm{~min}$. PCR products were separated on a $1 \%$ agarose gel in $1 \times$ Tris-acetate-EDTA buffer at $100 \mathrm{~V}$ for

Table 1. Sequences of the primers used in this study

\begin{tabular}{llcc}
\hline Primer name & \multicolumn{1}{c}{ Sequence $\left(\mathbf{5}^{\prime}-\mathbf{3}^{\prime}\right)$} & Expected size (bp) & Reference \\
\hline Bc.SdhB-F1 & AAGGTATCTGCGGCAGTTGT & 850 & This study \\
IpBecEnd2 & CTCATCAAGCCCCCTCATTGATATC & $\ldots$ & 26 \\
H272R-F & AAGGAGGATCGTAAGAAGCTTG & 232 & 48 \\
H272R-rev & TCGAGCAGTTGAGAATAGTGC & $\ldots$ & $\ldots$ \\
H272Y-fw & ATCTTGCCCCTCCTACTGGT & 220 & This study \\
H272Y-rev & CTCCAGCAGTTGAGAATAGTGTA & $\ldots$ & $\ldots$ \\
N230I-fw & TCTACCCACTACCCCACACC & 430 & This study \\
N230I-rev & TCCGCAATTGCCAAACCAGGATTC & $\ldots$ & $\ldots$ \\
\hline
\end{tabular}


30 min. Resulting PCR products were purified using ExoSap-IT reagent (USB-Affymetrix) and sequenced at the University of Florida Interdisciplinary Center for Biotechnology Research. Sequences were assembled with BioEdit version 7.0.9.0 (21), translated, and aligned using ClustalW2.

Sequence alignment revealed the substitution of a histidine at codon 272 of the $\mathrm{SdhB}$ by either an arginine $\left(\mathrm{B}^{\mathrm{H} 272 \mathrm{R}}\right)$, a tyrosine $\left(\mathrm{B}^{\mathrm{H} 272 \mathrm{Y}}\right)$, or a leucine $\left(\mathrm{B}^{\mathrm{H} 272 \mathrm{~L}}\right)$ in resistant isolates. Two other mutations were observed at codons 225 and 230, as described below. An allele-specific PCR assay developed previously (48) was used to specifically characterize the $\mathrm{B}^{\mathrm{H} 272 \mathrm{R}}$ and $\mathrm{B}^{\mathrm{H} 272 \mathrm{Y}}$ mutations in the remaining isolates. The primer pairs $\mathrm{H} 272 \mathrm{R}-\mathrm{F} / \mathrm{H} 272-\mathrm{rev}$ and H272Y-fw/H272Y-rev were used to amplify a fragment of the $s d h B$ gene from isolates harboring the $\mathrm{B}^{\mathrm{H} 272 \mathrm{R}}$ and $\mathrm{B}^{\mathrm{H} 272 \mathrm{Y}}$ mutations, respectively. The primer $\mathrm{H} 272 \mathrm{Y}-\mathrm{fw}$ was designed in this study to amplify a fragment slightly shorter than that obtained for $\mathrm{B}^{\mathrm{H} 272 \mathrm{R}}$ while one base was added at the $3^{\prime}$ end of the primer H272Y-rev (48) to increase its specificity. The same PCR reactions and conditions described above were used, except that the annealing temperatures were 67 and $68^{\circ} \mathrm{C}$ to detect the $\mathrm{B}^{\mathrm{H} 272 \mathrm{R}}$ and $\mathrm{B}^{\mathrm{H} 272 \mathrm{Y}}$ mutations, respectively. A PCR restriction fragment length polymorphism (PCR-RFLP) assay was developed to investigate the substitution of asparagine by isoleucine at codon $230\left(\mathrm{~B}^{\mathrm{N} 230 \mathrm{I}}\right)$ based on the presence of a unique HypCH4II restriction site (CAN/GT) in wild-type (WT) isolates. The primer pair N230Ifw/N230I-rev was developed and used to amplify a 400-bp fragment including codon 230 using the same aforementioned parameters, except that an annealing temperature of $60^{\circ} \mathrm{C}$ for $50 \mathrm{~s}$ was used. HypCH4II (New England BioLabs) digestions were carried out following the manufacturer's protocol. There were no restriction sites at codon 225 in B. cinerea isolates from Florida, allowing development of a PCR-RFLP assay for detection of the $\mathrm{B}^{\mathrm{P} 225 \mathrm{~F}}$ mutation.

In vivo assays and fitness studies. The efficacy of four SDHIs in controlling gray mold was evaluated in $12 \mathrm{~B}$. cinerea isolates with or without a mutation in the SdhB subunit. Efficacy tests were conducted on detached fruit prepared and inoculated as described previously (3), except that blackberry fruit were used instead of strawberry. Fruit were sprayed preventively with fluopyram (Luna Privilege), penthiopyrad (Fontelis), or fluxapyroxad (Xemium) at $531,1,877$, or $540 \mu \mathrm{l} /$ liter, respectively, or with boscalid (Endura) at $0.86 \mathrm{~g} /$ liter. Control fruit were sprayed with sterile water. Six

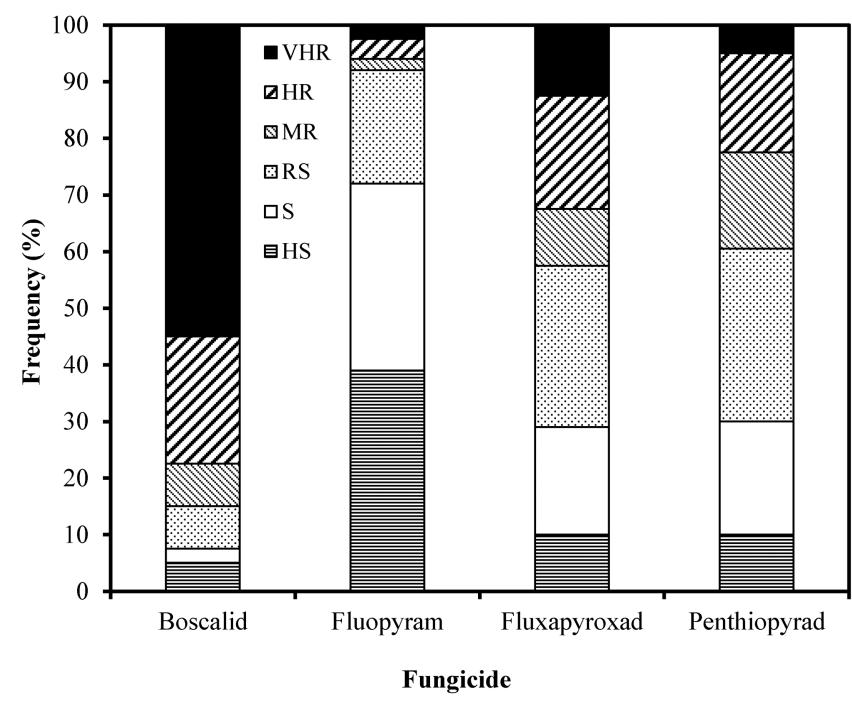

Fig. 1. Frequency of sensitive and resistant phenotypes in Botrytis cinerea isolates $(n=200)$ collected from strawberry fields in Florida between 2005 and 2012. HS, S, RS, MR, HR, and VHR refer to isolates highly sensitive, sensitive, with reduced sensitivity, moderately resistant, highly, and very highly resistant, respectively, based on resistance factor (RF). Respective RFs for boscalid were $<2,2$ to $5,>5$ to $20,>20$ to $100,>100$ to 1,000 , and $>1,000$. For fluopyram, fluxapyroxad, and penthiopyrad, the respective RFs were $<2,2$ to $5,>5$ to $20,>50$ to 100 , and $>100$. replicate fruit were used for each isolate-fungicide combination and the experiment was done in triplicate. Disease incidence was calculated as percent infected fruit relative to the control. Isolates that were not controlled by the recommended field rate (RFR) of fluopyram, fluxapyroxad, and penthiopyrad were tested with rates two and four times higher than the RFR of each of these three SDHIs.

Six fitness parameters (i.e., spore germination, mycelial growth, sporulation in vitro and in vivo, sclerotia production and osmotic sensitivity) were evaluated in 37 isolates (i.e., eight WT isolates, eight isolates for each of the H272R, H272Y, and N230I genotypes, and five isolates for the $\mathrm{P} 225 \mathrm{~F}$ genotype). All parameters, except sporulation on fruit, were evaluated at 22 and $30^{\circ} \mathrm{C}$ to mimic the average conditions occurring during the strawberry growing season between October and March and those occurring during the summer in Florida, respectively. To test for mycelial growth, two 5-mm-diameter mycelial plugs taken from the edge of a growing colony of each isolate were placed upside down on a plate containing either PDA or an intermediate medium (IM) containing $\mathrm{MgSO}_{4} \cdot 7 \mathrm{H}_{2} \mathrm{O}$ at $2 \mathrm{~g} /$ liter, glucose at $4 \mathrm{~g} /$ liter, peptone at $4 \mathrm{~g} /$ liter, $\mathrm{KH}_{2} \mathrm{PO}_{4}$ at $0.75 \mathrm{~g} /$ liter, citric acid at $2 \mathrm{~g} /$ liter, agar at 12 $\mathrm{g} /$ liter, and $0.02 \%$ Tween 20 . PDA is considered as a rich medium whereas the IM was reported previously to mimic plant substrates (32). Radial growth was measured after 4 days of incubation at $22^{\circ} \mathrm{C}$ and eight plates were used for each isolate-mediumtemperature combination. Production of sclerotia was evaluated after 30 days of incubation on the same plates used for the mycelial growth assay. Spore germination was tested on two WA (2\%) plates for each isolate-temperature combination, as described previously (1). Sporulation in vitro was evaluated on malt yeast agar (MYA) plates inoculated with mycelium plugs as described above, using four plates for each isolate-temperature combination. After 10 days of incubation, $15 \mathrm{ml}$ of sterile distilled water were added to each plate, and conidia were carefully scraped from the MYA surface, filtered through cheesecloth, and counted using a hemacytometer. Sporulation on fruit was evaluated on detached fruit prepared and inoculated as described previously (3). After 5 days of incubation at $22^{\circ} \mathrm{C}$, conidia were scraped from the fruit surface using a sterile cotton swab and resuspended in $1 \mathrm{ml}$ of sterile distilled water. Spores were counted as described for in vitro sporulation tests. The sensitivity to osmotic stress was evaluated on PDA amended with $\mathrm{NaCl}$ at $60 \mathrm{~g} /$ liter as described above for mycelium growth tests. All tests were conducted at least twice.

Data analysis. Data from in vitro sensitivity tests from repeated experiments were combined after homogeneity of variance between experiments was tested using Bartlett's test. Regression analyses and Pearson correlation coefficients were used to determine cross-resistance between different SDHIs. Data from the fruit and fitness studies were subjected to an analysis of variance and means were separated using Fisher's least significant difference test. All statistical analyses were performed using the SAS software (version 9.2; SAS Institute Inc.).

\section{Results}

Sensitivity and cross-resistance between SDHIs in B. cinerea field isolates. Isolates with RFs $\leq 2$ and between 2 and 5 for the four SDHIs were considered as HS and S, respectively. Among 200 isolates tested by determining their $\mathrm{EC}_{50}$ values, seven (3.5\%) and five $(2.5 \%)$ were $\mathrm{HS}$ or $\mathrm{S}$ to boscalid, respectively, whereas 11 isolates $(5.5 \%)$ showed $\mathrm{RS}$ ( $\mathrm{RF}=>5$ to 20) (Fig. 1). In total, 177 $(88.5 \%)$ were resistant to boscalid, of which $9.5,26.5$, and $52 \%$ were $\mathrm{MR}(\mathrm{RF}=>20$ to 100$)$, $\mathrm{HR}(\mathrm{RF}=>100$ to 1,000$)$, and very highly resistant (VHR, RF $>1,000$ ), respectively. In total, 76 $(38 \%)$ and 68 isolates $(34 \%)$ were HS or S to fluopyram whereas 39 isolates $(19.5 \%)$ had RS. Only 14 isolates (7\%) were resistant to fluopyram; that is, 3,6 , and 5 isolates were $\mathrm{MR}, \mathrm{HR}(\mathrm{RF}=>50$ to 100), and VHR (RF > 100), respectively (Fig. 1). These isolates were resistant to all four SDHIs as well. In contrast with fluopyram, only $10 \%$ of isolates were HS to fluxapyroxad and penthiopyrad, whereas $20 \%$ were S (Fig. 1). The highest 
frequencies of isolates with RS were observed for penthiopyrad $(30.5 \%)$ and fluxapyroxad $(28.5 \%)$. Overall, RFs were slightly lower for penthiopyrad compared with fluxapyroxad, resulting in 17, 17.5, and 5\% MR, HR, or VHR isolates versus 10, 20, and $12.5 \%$, respectively.

Of the 454 isolates screened using discriminatory doses in 2012 and 2013 , resistance frequencies to boscalid were 54.5 to $100 \%$ across locations and years (data not shown). Resistance frequencies to penthiopyrad and fluxapyroxad ranged from $0 \%$ in the ASB location to $35 \%$ in the BY location in 2012 and from $16.7 \%$ in the ST location to $54.2 \%$ in the HL location in 2013 (Fig. 2A). In four locations (FS, FY, PC, and SS) where resistance to boscalid has been monitored since 2010 and during the 2013 season, when penthiopyrad was used for the first time, resistance frequency to the latter increased slightly in all locations between 2012 and 2013 (Fig. 2B). The highest increase (7.3\%) was observed in the FS location followed by the FY (5.9\%). All isolates that were resistant to penthiopyrad were also resistant to fluxapyroxad and boscalid (data not shown). Resistance to fluopyram was detected in GC, PC, FY, and SS at frequencies of 1.7, 4.5, 4.9, and 2.9\%, respectively, in 2012; and in FS, DH, GT, and DM locations at frequencies of 5.0, 8.7, 8.3, and 8.3\%, respectively, in 2013.

Regression analyses (Fig. 3) and Pearson correlation tests indicated no significant cross-resistance between fluopyram and each of boscalid $(r=0.03, P=0.710)$, penthiopyrad $(r=0.188, P=$ $0.112)$, and fluxapyroxad $(r=0.179, P=0.113)$. Strong correlations were between boscalid and penthiopyrad $(r=0.480$, $P<0.001)$ and between boscalid and fluxapyroxad $(r=0.529, P$ $<0.001)$ and the highest correlation was between fluxapyroxad and penthiopyrad ( $r=0.865, P<0.0001$ ), which was confirmed by regression analysis (Fig. 3A-D). Significant positive crossresistance was observed between all SDHIs in a separate analysis including the 14 isolates resistant to all SDHIs (data not shown).

Characterization and frequency of $S d h B$ mutations in $B$. cinerea field isolates. Alignment of the $\mathrm{SdhB}$ amino acid sequences from 30 isolates exhibiting different sensitivity phenotypes revealed the presence of three mutations at codons 225,230 , and 272. The sequence alignment from sequenced isolates is shown in Supplementary Figure 2 . The histidine was replaced by an arginine $\left(\mathrm{B}^{\mathrm{H} 272 \mathrm{R}}\right)$, a tyrosine $\left(\mathrm{B}^{\mathrm{H} 272 \mathrm{Y}}\right)$, or a leucine $\left(\mathrm{B}^{\mathrm{H} 272 \mathrm{~L}}\right)$, in 10,7 , and 1 isolate, respectively. In two isolates, the proline at codon 225 was replaced by a phenylalanine $\left(\mathrm{B}^{\mathrm{P} 225 \mathrm{~F}}\right)$ whereas, in four isolates, the asparagine at codon 230 was replaced by an isoleucine $\left(\mathrm{B}^{\mathrm{N} 230 \mathrm{I}}\right)$. The latter was characterized in other isolates using a PCR-RFLP assay. The primer pair N230I-fw/N230I-rev amplified a 430-bp fragment of the SdhB, including codon 230. HypCH4II digestions resulted in two bands of 240 and $190 \mathrm{bp}$ in isolates without the N230I mutation and $430 \mathrm{bp}$ in isolates carrying the N230I mutation following visualization on a $3 \%$ agarose gel (Fig. 4).

Of 200 isolates investigated for mutations in the SdhB using allele-specific and PCR-RFLP assays, no mutation was observed in the SdhB of isolates characterized as HS, S, or RS to all fungicides. Interestingly, no mutation was detected in four isolates that were MR to boscalid (Supplementary Table 1). The $\mathrm{B}^{\mathrm{H} 272 \mathrm{R}}$ mutation was found in 103 isolates $(51.5 \%)$ resistant to boscalid (Table 2). The $\mathrm{B}^{\mathrm{H} 272 \mathrm{Y}}$ mutation was detected in 56 isolates $(28 \%)$ simultaneously resistant to boscalid, fluxapyroxad, and penthiopyrad. Among the 14 isolates resistant to all SDHIs, 5 had the proline at codon 225 replaced by phenylalanine $\left(\mathrm{B}^{\mathrm{P} 225 \mathrm{~F}}\right), 8$ had the asparagine at codon 230 replaced by an isoleucine $\left(\mathrm{B}^{\mathrm{N} 230 \mathrm{I}}\right)$, and 1 had the histidine at codon 272 replaced by a leucine $\left(\mathrm{B}^{\mathrm{H} 272 \mathrm{~L}}\right)$ (Table 2;). All $\mathrm{B}^{\mathrm{N} 230 \mathrm{I}}$ isolates were either $\mathrm{HR}$ or VHR to boscalid and fluxapyroxad and MR or HR to fluopyram, whereas the three resistance phenotypes were observed for penthiopyrad. All $\mathrm{B}^{\mathrm{P} 225 \mathrm{~F}}$ were VHR to boscalid, fluxapyroxad, and fluopyram and either HR or VHR to penthiopyrad (Table 2).

Fruit assay and fitness parameters. Boscalid fully controlled the HS isolates and significantly reduced disease incidence of the $S$ isolate (12-241) but failed to control any of the other mutant types (Table 3). Fluopyram applied preventively at the RFR controlled the WT isolates as well as the $\mathrm{B}^{\mathrm{H} 272 \mathrm{R}}$ and $\mathrm{B}^{\mathrm{H} 272 \mathrm{Y}}$ isolates but failed to control the $\mathrm{B}^{\mathrm{N} 230 \mathrm{I}}$ and $\mathrm{B}^{\mathrm{P} 225 \mathrm{~F}}$ mutants, and the latter were not controlled even when a double rate of fluopyram was applied (data not shown). Fluxapyroxad fully controlled the HS isolates and the $\mathrm{B}^{\mathrm{H} 272 \mathrm{R}}$ mutants but not the $\mathrm{S}$ isolate (12-241) whereas penthiopyrad failed to fully control the $S$ isolate $(12-241)$ and the $H R B^{\mathrm{H} 272 R}$ isolate 10-35 (Table 3). Sporulation of HS isolates was fully inhibited by all fungicides whereas the $\mathrm{S}$ isolate (12-241) was fully inhibited by fluopyram only (Table 3 ). Significant differences were observed in sporulation inhibition between isolates within the same genotype, with the exception of the $\mathrm{B}^{\mathrm{H} 272 \mathrm{R}}$ for the three newer SDHIs. Overall, fluxapyroxad reduced sporulation more than penthiopyrad and boscalid.

The fitness parameters of the different isolates were affected differentially and our results do not support major fitness cost due to mutations in the SdhB subunit compared with the WT isolates

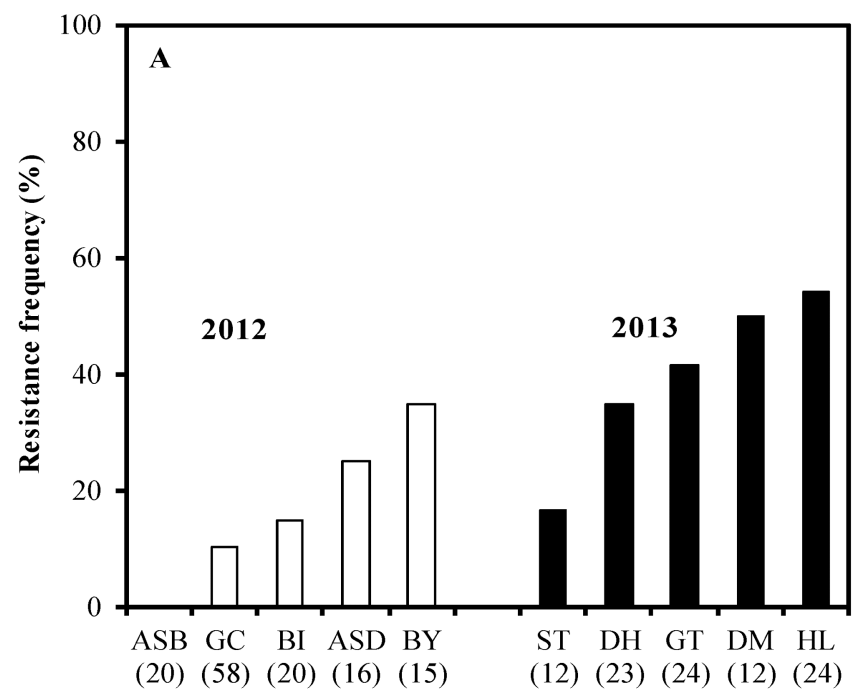

Location (number of isolates)

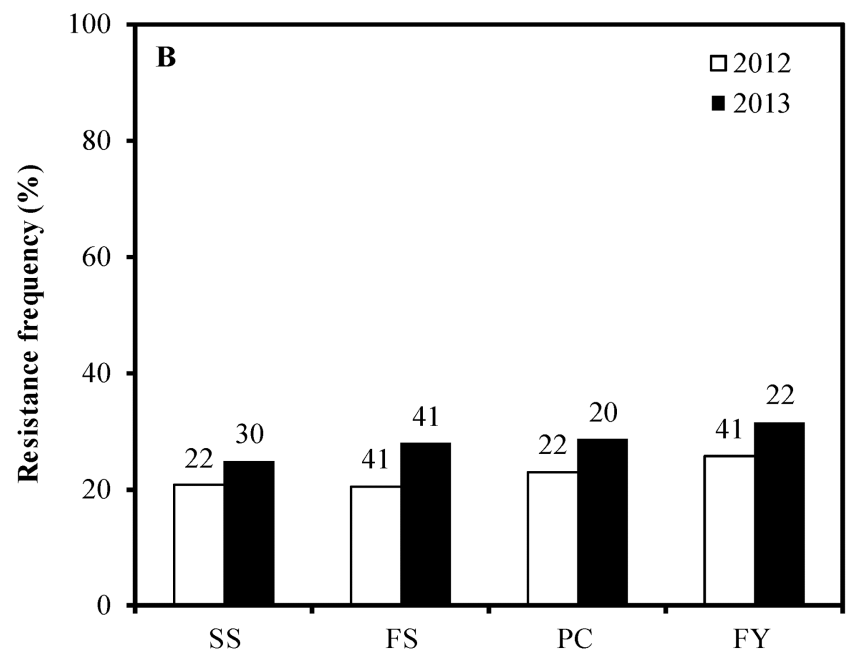

Location

Fig. 2. A, Frequency of resistance to penthiopyrad and fluxapyroxad in Botrytis cinerea isolates collected across locations (ASB, GC, BI, ASD, BY, ST, DH, GT, $\mathrm{DM}$, and $\mathrm{HL}$ ) in 2012 and 2013. The number below the location name indicates the number of isolates for each location. B, Frequency of resistance to penthiopyrad across four locations (SS, FS, PC, and FY) never sprayed with penthiopyrad in 2011-12 and in the same locations following penthiopyrad use in the 2012-13 season. Numbers on the top of each bar indicate the number of isolates tested from each location. Isolates were discriminated based on mycelial growth inhibition tests on potato dextrose agar amended with penthiopyrad at $50 \mu \mathrm{g} / \mathrm{ml}$. Isolates inhibited less than $50 \%$ were considered resistant. 
(Table 4). All mutants grew significantly faster than the WT isolates on PDA and IM media, except the $\mathrm{B}^{\mathrm{N} 230 \mathrm{I}}$ isolates on IM. The $\mathrm{B}^{\mathrm{H} 272 \mathrm{R}}$ and $\mathrm{B}^{\mathrm{P} 225 \mathrm{~F}}$ mutants were most sensitive to osmotic stress compared with the wilt-types and the two other genotypes. All mutants sporulated better than the WT isolates on MYA and equally on fruit, except for $\mathrm{B}^{\mathrm{P} 225 \mathrm{~F}}$ (Table 4). The WT isolates produced more sclerotia than the mutants on PDA and equal numbers on IM, except for $\mathrm{B}^{\mathrm{P} 225 \mathrm{~F}}$. No significant differences were observed in conidial germination between all genotypes (data not shown). Mycelium growth was reduced significantly at $30^{\circ} \mathrm{C}$ for all isolates whereas all other fitness parameters were completely inhibited at this temperature (data not shown).

\section{Discussion}

The SDHIs penthiopyrad, fluxapyroxad, and fluopyram had a higher intrinsic activity against $B$. cinerea than boscalid. Fluopyram was most active, with overall RFs 500 times lower than boscalid and a greater control in vivo. Comparatively, penthiopyrad and fluxapyroxad had RFs 25 to 50 times lower than boscalid. High efficacy of the newer SDHIs has been documented in $\mathrm{B}$. $\mathrm{ci}$ nerea $(2,42,44)$ and in other fungi $(8,10,13,15,17,23,35,47)$. The biological spectrum and the intrinsic activity of the different SDHIs are mainly defined by their docking ability and affinity to the target site. This affinity is highly influenced by the chemical structure of the fungicide. Penthiopyrad and fluxapyroxad share a very similar active residue whereas fluopyram possesses an active residue (benzamide moiety) different from the three other SDHIs. The importance of the chemical structure on the biological activity was shown for fluopyram when a replacement of the 3-chloro-5trifluoromethyl-2-pyridinyl residue (Supplementary Figure 1, shaded), by a 2-chloro-4-trifluoromethyl-phenyl residue caused a significant decrease in its anti-ascomycete activity whereas its antibasidiomycete activity was recovered when the same residue was replaced by an ortho-substituted-phenyl ring (35). In M. graminicola, fluopyram had a binding energy lower than boscalid and penthiopyrad suggesting tighter binding of the former to the quinone-binding site (Qp) (17). These authors reported that the benzamide moiety of fluopyram facilitates extended binding of this fungicide to the residues from the $\mathrm{SdhB}$ and $\mathrm{SdhC}$ subunits forming the $\mathrm{Q}$ pocket, suggesting that potential amino-acid alterations in both subunits may affect the efficacy of this SDHI. Moreover, the relatively higher RFs observed for fluxapyroxad compared with penthiopyrad may suggest a weaker accepting group for the former or a higher inherent activity for the latter.

We present evidence for existing risks for resistance development to the new SDHIs in $B$. cinerea because of cross-resistance with boscalid. Cross-resistance between boscalid and penthiopyrad but not with fluopyram was confirmed in previous reports in Alternaria alternata, Didymella bryoniae, $M$. graminicola, and Corynespora cassiicola $(6,17,23)$. In a study including $192 \mathrm{~B}$. cinerea isolates from grape, kiwi, tomato, and cucumber but not

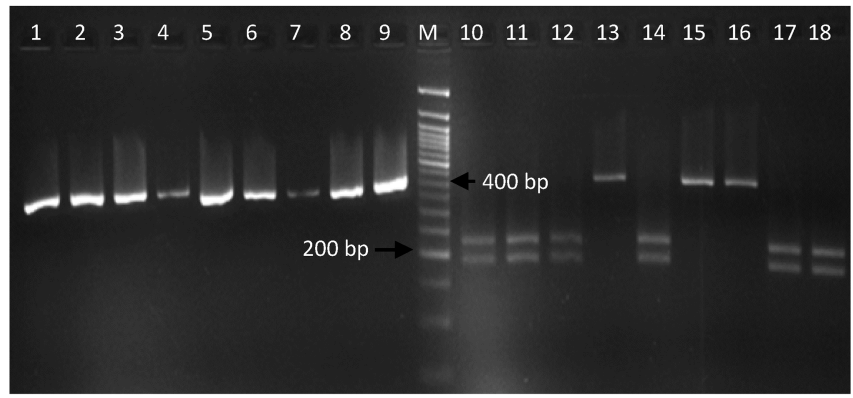

Fig. 4. Gel electrophoresis (3\% agarose) of undigested (lanes 1 to 9 ) and HypCH4II-digested (lanes 10 to 18) SdhB polymerase chain reaction fragments amplified using the primer set N230l-fw/N230l-rev. Lanes 10-12, 14, 17, and 18 show isolates of Botrytis cinerea without mutation at codon 230 in the SdhB; lanes 13,15 , and 16 show isolates carrying a $\mathrm{N} 230 \mathrm{l}$ mutation at codon $230 . \mathrm{M}=$ molecular marker.
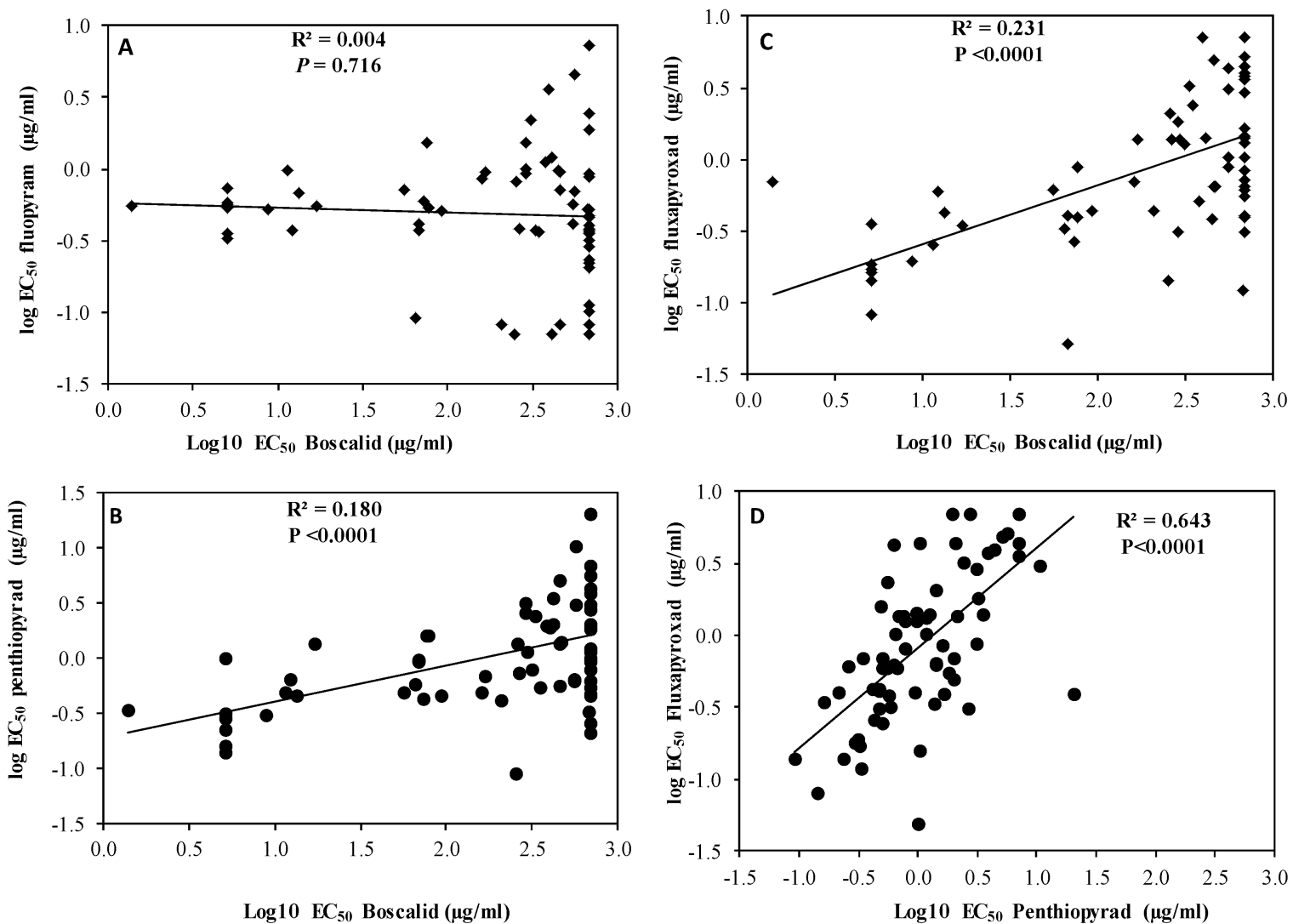

Fig. 3. Regression of $\log _{10}$ effective concentrations necessary to inhibit $50 \%$ germination or growth $\left(\mathrm{EC}_{50}\right)$ of Botrytis cinerea isolates $(n=100)$ for boscalid on those for $A$, fluopyram; $\mathbf{B}$, penthiopyrad; and $\mathbf{C}$, fluxapyroxad and $\mathbf{D}$, those of penthiopyrad to fluxapyroxad. 
strawberry, cross-resistance was absent between boscalid and fluopyram (42). However, in a more recent study, cross-resistance was documented between boscalid, fluopyram, and fluxapyroxad in B. cinerea isolates carrying certain mutations in the $\mathrm{SdhB}$ (44). To the best of our knowledge, this is the first report on sensitivity to penthiopyrad and on cross-resistance with boscalid in $\mathrm{B}$. $\mathrm{ci}$ nerea. Cross-resistance is conferred, in most fungi, by mutations in the SdhB that allow similarities in docking to multiple SDHIs. Our findings on five amino-acid substitutions $\left(\mathrm{B}^{\mathrm{H} 272 \mathrm{R}}, \mathrm{B}^{\mathrm{H} 272 \mathrm{Y}}, \mathrm{B}^{\mathrm{H} 272 \mathrm{~L}}\right.$, $\mathrm{B}^{\mathrm{P} 225 \mathrm{~F}}$, and $\mathrm{B}^{\mathrm{N} 230 \mathrm{I}}$ ) conferring resistance to boscalid and four substitutions $\left(\mathrm{B}^{\mathrm{H} 272 \mathrm{Y}}, \mathrm{B}^{\mathrm{H} 272 \mathrm{~L}}, \mathrm{~B}^{\mathrm{P} 225 \mathrm{~F}}\right.$, and $\left.\mathrm{B}^{\mathrm{N} 230 \mathrm{I}}\right)$ differentially confer- ring resistance to penthiopyrad, fluxapyroxad, and fluopyram agree with previous reports $(26,36,43,48)$.

Although isolates from the most predominant genotype $\left(\mathrm{B}^{\mathrm{H} 272 \mathrm{R}}\right)$ were sensitive to all three new SDHIs, a significant fraction (27 to $63 \%$ ) of these mutants showed RS (RF up to 20) and even MR (3 to $23 \%$ ) to these SDHIs. The presence of an arginine residue at codon 272 does not seem to interfere directly with the activity of the newer SDHIs. However, such mutations may cause conformational changes in the SDH protein which may decrease the affinity of the fungicide with the target site. On the other hand, the higher level of resistance conferred by the $\mathrm{B}^{\mathrm{H} 272 \mathrm{Y}}$ to boscalid, penthiopy-

Table 2. Key mutations in the iron-sulfur SdhB subunit of Botrytis cinerea field isolates and their sensitivity to four succinate dehydrogenase inhibitors

\begin{tabular}{|c|c|c|c|c|c|c|c|c|c|c|c|}
\hline \multirow[b]{3}{*}{ SdhB } & & & \multirow[b]{3}{*}{$n^{\mathbf{z}}$} & \multicolumn{8}{|c|}{ Sensitivity $\left(\mathrm{EC}_{50}[\mu \mathrm{g} / \mathrm{ml}]\right)$ to $^{\mathrm{w}}$} \\
\hline & \multicolumn{2}{|c|}{ Change $^{x}$} & & \multicolumn{2}{|c|}{ Boscalid } & \multicolumn{2}{|c|}{ Fluopyram } & \multicolumn{2}{|c|}{ Fluxapyroxad } & \multicolumn{2}{|c|}{ Penthiopyrad } \\
\hline & WT $^{y}$ & Mutant & & Range & Mean & Range & Mean & Range & Mean & Range & Mean \\
\hline Wild type & CAC & $\ldots$ & 27 & $0.28-17.0$ & 3.55 & $0.16-0.92$ & 0.57 & $0.08-1.34$ & 0.38 & $0.14-1.59$ & 0.65 \\
\hline Mutant & & & & & & & & & & & \\
\hline $\mathrm{B}^{\mathrm{H} 272 \mathrm{R}}$ & $\mathrm{CAC}$ & CGC & 103 & $6.89->688$ & $>302.49$ & $0.07-4.53$ & 1.34 & $0.14-4.36$ & 1.34 & $0.21-4.18$ & 1.33 \\
\hline $\mathrm{B}^{\mathrm{H} 272 \mathrm{Y}}$ & CAC & TAC & 56 & $36.8->688$ & $>342.99$ & $0.07-2.39$ & 0.49 & $5.18-21.63$ & 9.59 & $5.51-19.47$ & 8.09 \\
\hline $\mathrm{B}^{\mathrm{H} 272 \mathrm{~L}}$ & $\mathrm{CAC}$ & CTC & 1 & $\ldots$ & $>688$ & 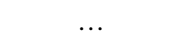 & 9.92 & 列 & 5.61 & & 12.75 \\
\hline $\mathrm{B}^{\mathrm{N} 230 \mathrm{I}}$ & AAC & ATC & 8 & $235.9->688$ & 449.56 & $5.02-13.09$ & 10.55 & $5.48-15.23$ & 10.29 & $5.46-8.44$ & 6.99 \\
\hline $\mathrm{B}^{\mathrm{P} 225 \mathrm{~F}}$ & $\mathrm{CCC}$ & TTC & 5 & $589.4->688$ & $>512.56$ & $56.58->143.21$ & 98.52 & $>141.71$ & $>141.71$ & $9.97-14.93$ & 13.12 \\
\hline
\end{tabular}

${ }^{w}$ Effective concentration of each fungicide necessary to inhibit germination or mycelial growth by $50 \%$ compared with a control without fungicide.

${ }^{x}$ Associated nucleotide change in the SdhB.

y Wild type.

${ }^{\mathrm{z}}$ Number of isolates from each group.

Table 3. Efficacy of boscalid, fluopyram, fluxapyroxad, and penthiopyrad in reducing gray mold incidence and sporulation on detached fruit

\begin{tabular}{|c|c|c|c|c|c|c|c|c|c|c|}
\hline \multirow[b]{2}{*}{$\operatorname{SdhB}^{y}$} & \multirow[b]{2}{*}{ Isolate } & \multirow[b]{2}{*}{ Phen $^{z}$} & \multicolumn{4}{|c|}{ Disease incidence $(\%)^{\mathrm{w}}$} & \multicolumn{4}{|c|}{ Sporulation inhibition $^{x}$} \\
\hline & & & Boscalid & Fluopyram & Fluxapyroxad & Penthiopyrad & Boscalid & Fluopyram & Fluxapyroxad & Penthiopyrad \\
\hline \multirow[t]{3}{*}{ WT } & $11-45$ & HS & 0.0 & 0.0 & 0.0 & 0.0 & $100.0 \mathrm{a}$ & $100.0 \mathrm{a}$ & $100.0 \mathrm{a}$ & $100.0 \mathrm{a}$ \\
\hline & $12-221$ & HS & 0.0 & 0.0 & 0.0 & 0.0 & $100.0 \mathrm{a}$ & $100.0 \mathrm{a}$ & $100.0 \mathrm{a}$ & $100.0 \mathrm{a}$ \\
\hline & $12-241$ & $\mathrm{~S}$ & 12.8 & 0.0 & 22.0 & 8.0 & $65.7 \mathrm{e}$ & $100.0 \mathrm{a}$ & $94.0 \mathrm{~b}$ & $88.0 \mathrm{~b}$ \\
\hline \multirow[t]{2}{*}{$\mathrm{B}^{\mathrm{H} 272 \mathrm{R}}$} & $11-67$ & MR & 80.0 & 0.0 & 0.0 & 0.0 & $60.86 \mathrm{f}$ & $100.0 \mathrm{a}$ & $98.1 \mathrm{a}$ & $100.0 \mathrm{a}$ \\
\hline & $10-35$ & HR & 100.0 & 0.0 & 0.0 & 12.5 & $34.26 \mathrm{~h}$ & $100.0 \mathrm{a}$ & $100.0 \mathrm{a}$ & $96.6 \mathrm{a}$ \\
\hline \multirow[t]{2}{*}{$\mathrm{B}^{\mathrm{H} 272 \mathrm{Y}}$} & $12-332$ & HR & 100.0 & 0.0 & 60.0 & 40.0 & $89.5 \mathrm{~b}$ & $100.0 \mathrm{a}$ & $100.0 \mathrm{a}$ & $98.4 \mathrm{a}$ \\
\hline & $12-65$ & VHR & 100.0 & 0.0 & 100.0 & 100.0 & $9.69 \mathrm{j}$ & $100.0 \mathrm{a}$ & $78.9 \mathrm{c}$ & $-31.4 \mathrm{f}$ \\
\hline \multirow[t]{2}{*}{$\mathrm{B}^{\mathrm{N} 230 \mathrm{I}}$} & $12-255$ & HR & 100.0 & 100.0 & 100.0 & 100.0 & $74.0 \mathrm{c}$ & $91.03 \mathrm{~b}$ & $73.9 \mathrm{~d}$ & $13.6 \mathrm{c}$ \\
\hline & $12-450$ & VHR & 100.0 & 100.0 & 100.0 & 100.0 & $69.8 \mathrm{~d}$ & $23.8 \mathrm{~d}$ & $70.4 \mathrm{e}$ & $-11.7 \mathrm{e}$ \\
\hline \multirow[t]{3}{*}{$\mathrm{B}^{\mathrm{P} 225 \mathrm{~F}}$} & $11-62$ & VHR & 100.0 & 100.0 & 100.0 & 100.0 & $45.6 \mathrm{~g}$ & $57.3 \mathrm{c}$ & $45.6 \mathrm{~g}$ & $-51.7 \mathrm{~g}$ \\
\hline & $12-355$ & VHR & 100.0 & 100.0 & 100.0 & 100.0 & $29.2 \mathrm{i}$ & $0.0 \mathrm{e}$ & $54.2 \mathrm{f}$ & $-62.8 \mathrm{~h}$ \\
\hline & $12-374$ & VHR & 100.0 & 100.0 & 100.0 & 100.0 & 64.5 ef & $-43.7 \mathrm{f}$ & $-30.46 \mathrm{~h}$ & $-7.6 \mathrm{~d}$ \\
\hline
\end{tabular}

${ }^{\mathrm{w}}$ Disease incidence (gray mold) expressed as percent of infected fruit relative to untreated control. Data are the mean of 18 values across three experimental runs.

${ }^{\mathrm{x}}$ Inhibition of sporulation by each fungicide relative to untreated control. Data are the mean of 12 values across three experimental runs. Values within the same column followed by the same letter are not significantly different based on ANOVA analyses and least significant difference tests at $P \leq 0.05$.

y $\mathrm{SdhB}$ genotype; $\mathrm{WT}=$ wild type.

${ }^{z}$ Phenotype was determined based on resistance factor to boscalid. HS = highly sensitive (resistance factor $[\mathrm{RF}]<2$ ), $\mathrm{S}=$ sensitive $(\mathrm{RF}=2$ to $<5), \mathrm{MR}=$ moderate resistance $(\mathrm{RF}=>20$ to 100$), \mathrm{HR}=$ highly resistant $(\mathrm{RF}=>100$ to 1,000$)$, and $\mathrm{VHR}=$ very highly resistant $(\mathrm{RF}>1,000)$.

Table 4. Fitness parameters associated with different amino acid alterations in the SdhB subunit of Botrytis cinerea field isolates ${ }^{\mathrm{w}}$

\begin{tabular}{|c|c|c|c|c|c|c|c|}
\hline \multirow[b]{2}{*}{ Genotype } & \multicolumn{3}{|c|}{ Mycelial growth $(\mathrm{mm})$ on $^{\mathrm{x}}$} & \multicolumn{2}{|c|}{ Sporulation (10E6) on ${ }^{y}$} & \multicolumn{2}{|c|}{ Number of sclerotia $^{z}$} \\
\hline & PDA & IM & $6 \% \mathrm{NaCl}$ & MYA & Fruit & PDA & IM \\
\hline Wild type & $31.2 \mathrm{~b}$ & $27.2 \mathrm{~b}$ & $12 \mathrm{~b}$ & $1.4 \mathrm{~b}$ & $6.7 \mathrm{ab}$ & $67.6 \mathrm{a}$ & $65.9 \mathrm{~b}$ \\
\hline $\mathrm{B}^{\mathrm{H} 272 \mathrm{R}}$ & $38.7 \mathrm{a}$ & $29.1 \mathrm{a}$ & $9.1 \mathrm{c}$ & $3.7 \mathrm{a}$ & $7.1 \mathrm{ab}$ & $52.9 \mathrm{~b}$ & $64.9 \mathrm{~b}$ \\
\hline $\mathrm{B}^{\mathrm{H} 272 \mathrm{Y}}$ & $39.2 \mathrm{a}$ & $28.8 \mathrm{a}$ & $16.3 \mathrm{a}$ & $4.1 \mathrm{a}$ & $5.7 \mathrm{bc}$ & $51.5 \mathrm{~b}$ & $74.3 \mathrm{~b}$ \\
\hline $\mathrm{B}^{\mathrm{N} 230 \mathrm{I}}$ & $40.2 \mathrm{a}$ & $25.3 \mathrm{c}$ & $15.7 \mathrm{a}$ & $4.9 \mathrm{a}$ & $8.7 \mathrm{a}$ & $10.6 \mathrm{c}$ & $48.8 \mathrm{~b}$ \\
\hline $\mathrm{B}^{\mathrm{P} 225 \mathrm{~F}}$ & $40.4 \mathrm{a}$ & $29.1 \mathrm{a}$ & $9.2 \mathrm{c}$ & $3.8 \mathrm{a}$ & $2.8 \mathrm{c}$ & $51.4 \mathrm{~b}$ & $170.9 \mathrm{a}$ \\
\hline LSD & 1.88 & 1.41 & 2.2 & 1.29 & 2.20 & 13.15 & 34.39 \\
\hline
\end{tabular}

${ }^{\mathrm{w}}$ Data for all fitness parameters are the mean from eight isolates used for each genotype, except for the $\mathrm{B}^{\mathrm{P} 225 \mathrm{~F}}$ genotype, for which five isolates were used. Values within the same column followed by same letters are not significantly different based on analysis of variance and least significant difference (LSD) test $(P=0.05)$.

${ }^{\mathrm{x}}$ Radial growth in $\mathrm{mm}$ after 4 days of incubation at $22^{\circ} \mathrm{C}$. Data are the mean of 16 values across three experimental runs. PDA $=$ potato dextrose agar and IM $=$ intermediate medium.

${ }^{y}$ Number of spores per plate after 10 and 5 days of incubation on malt yeast agar (MYA) or per fruit, respectively, at $22^{\circ} \mathrm{C}$. Data are the mean of eight values across two experimental runs.

${ }^{\mathrm{z}}$ Number of sclerotia per plate after 40 days of incubation at $22^{\circ} \mathrm{C}$. 
rad, and fluxapyroxad compared with fluopyram confirms previous reports $(26,36)$ and may suggest a higher affinity between the tyrosine and the acceptor group of penthiopyrad in addition to the absence of an H-bound acceptor in fluopyram, which relies more on the benzamide moiety for its extended binding $(26,36)$. Although the $\mathrm{B}^{\mathrm{H} 272 \mathrm{Y}}$ isolates were predominantly (77\%) HS to fluopyram, about $14 \%$ of the $\mathrm{B}^{\mathrm{H} 272 \mathrm{Y}}$ mutants, interestingly, showed RS to fluopyram. This is the first report on RS to fluopyram in the $\mathrm{B}^{\mathrm{H} 272 \mathrm{Y}}$ mutant group because all previous studies, using smaller populations, indicated HS of these mutants to fluopyram $(8,26,31,44)$. The ability of the $\mathrm{B}^{\mathrm{H} 272 \mathrm{R}}$ and $\mathrm{B}^{\mathrm{H} 272 \mathrm{Y}}$ isolates to adapt and develop resistance more quickly to new SDHIs and, more particularly, to fluopyram is not clear. Furthermore, in most phytopathogenic fungi, narrower resistance ranges have always been reported within the same mutant group $(6,7,23,31)$ compared with those reported herein and previously for $B$. cinerea. We found $\mathrm{B}^{\mathrm{H} 272 \mathrm{R}}$ to confer different levels of resistance, from MR to VHR, to boscalid whereas the $\mathrm{B}^{\mathrm{H} 272 \mathrm{Y}}$ mutation was found in HR and VHR isolates. The $\mathrm{B}^{\mathrm{H} 272 \mathrm{R}}$ and $\mathrm{B}^{\mathrm{H} 272 \mathrm{Y}}$ mutations conferred low to very high resistance in $B$. cinerea population from apples (48) or only moderate resistance to boscalid in populations from grape and strawberry $(26,43)$. Although different methodologies may account for some of these disparities, other mechanisms (i.e., mutations in the other SDH subunits particular to $B$. cinerea that may interfere with the docking and sensitivity to the SDHIs) require further investigation.

In addition to the $\mathrm{B}^{\mathrm{H} 272 \mathrm{~L}}$ mutation, present at a very low frequency $(0.5 \%)$ in Florida, mutations occurring at codons 225 and 230 , only reported in B. cinerea and lab mutants of $M$. graminicola (at codons 220 and 225), are more critical because they confer resistance to all four SDHIs tested in this study as well as to several SDHIs currently used in agriculture $(36,44)$. Regardless of the resistance level observed in vitro, isolates carrying these mutations were not controlled in vivo with the RFR of the SDHIs or even when a double rate was applied (data not shown). The high level of resistance conferred by the $\mathrm{B}^{225 \mathrm{~F}}$ and $\mathrm{B}^{230 \mathrm{I}}$ mutations to all SDHIs, including those never sprayed in the field, indicate a key role of theses amino acids in SDHI docking. Both P255F and N230I mutations are located in the highly conserved CPSYWWN motif. In $M$. graminicola, the P220, W223, and W224 residues, equivalent to $\mathrm{P} 225$, W228, and W229 (next to the N230) in B. cinerea, were predicted to form hydrogen bounds with SDHIs (36). However, the fact that these mutants are found at low frequencies compared with those carrying the $\mathrm{H} 272$ mutations may be explained by the fact that boscalid and other SDHIs preferably dock deeper in the Qp $(36,39)$ and, therefore, are in a direct interaction with the $\mathrm{H} 272$ residue, also located deeper in the Qp, which ultimately exercises more pressure on this residue. Interestingly, recent in vitro studies showed that fluopyram selects for mutants with residue changes in the SdhC subunit more frequently than the P225 or N230I in the $\mathrm{SdhB}$ in M. graminicola (36). Moreover, phenylalanine, isoleucine, and leucine are known to be highly hydrophobic compared with arginine and especially tyrosine, which is considered to be the least hydrophobic. Whether a change in hydrophobicity of the protein affects the topography or redox potential of the SDH enzyme and, therefore, favors the docking to other amino acids forming the $\mathrm{Q}$ pocket needs further investigation. Our findings agree with those of Veloukas et al. (44) with regard to the $\mathrm{B}^{\mathrm{P} 225 \mathrm{~F}}$ mutants but not with the $\mathrm{B}^{\mathrm{N} 230 \mathrm{I}}$ mutants. We found the latter to be HR to VHR to boscalid, MR or HR to fluopyram, and HR to VHR to penthiopyrad and fluxapyroxad and with high disease incidence in vivo, although the sporulation of one these mutants was significantly reduced compared with the $\mathrm{B}^{\mathrm{P} 225 \mathrm{~F}}$ mutants. Veloukas et al. (44) reported that the $\mathrm{B}^{\mathrm{N} 230 \mathrm{I}}$ mutants had low resistance to most SDHIs and MR to boscalid in vitro, and the one isolate tested in vivo showed significantly lower disease incidence on fruit sprayed with boscalid and fluopyram. Possible explanations include differences in sensitivity of germ tube and mycelium and the medium used to characterize these mutants as well as differences in pathogenicity on blackberry and strawberry. Future investigations including a larger number of the $\mathrm{B}^{\mathrm{N} 230 \mathrm{I}}$ mutants will certainly help understand and measure their real risk.

Results from early resistance monitoring in fields sprayed with penthiopyrad (Fontelis) for the first time in 2013 in Florida warrant careful use of the new SDHIs. The slight increase in penthiopyrad resistance frequencies within 1 year of use suggests that this SDHI and its relatives may quickly select for additional resistant populations in the field. A 6 to $9 \%$ increase was observed in two locations where penthiopyrad was used twice a season compared with 3 to $5 \%$ in those where penthiopyrad was used once only. Hence, restricting the use of penthiopyrad and fluxapyroxad to two applications, instead of four as recommended on the label, at full rate during the flowering period when weather conditions are moderately conducive to gray mold may delay quick selection for resistant populations. Due to its high efficacy, fluopyram, once registered, may be sprayed twice a season during bloom when conditions are highly conducive to gray mold development (27). Resistance management will be required and may include rotation with fungicides having different modes of action, including multisite fungicides which have been recently found to extend the life of the SDHIs longer than single-site fungicides (22).

Compared with the WT isolates, no evidence of major fitness costs was associated with the different mutations detected in the $\mathrm{SdhB}$ of B. cinerea, similar to previous reports on other fungal plant pathogens $(5,17,30,36,41)$. Although the SDH enzyme activity was significantly impacted in $M$. graminicola harboring different mutations in the SDHB, C, and D subunits, no major fitness cost was reported (36). Fitness abilities of the $B$. cinerea mutants were similar or better than those of WT isolates in the absence of fungicide pressure, as seen herein. This suggests that selection pressure in the field may favor the mutants and make disease management more difficult. The use of boscalid in commercial strawberry fields in Florida has been reduced following reports of widespread resistance. It would be interesting to follow the ability of the $\mathrm{B}^{\mathrm{H} 272 \mathrm{R}}$ mutants to persist under lower selection pressure. Our data also warrant appropriate use of the new SDHIs to avoid quick selection for the $\mathrm{B}^{\mathrm{H} 272 \mathrm{Y} / \mathrm{L}}, \mathrm{B}^{\mathrm{P} 225 \mathrm{~F}}$, and $\mathrm{B}^{\mathrm{N} 230 \mathrm{I}}$ mutants, which seem to have no fitness cost. The suppression of fitness parameters of $B$. cinerea at temperatures around $30^{\circ} \mathrm{C}$ (data not shown) strongly supports evidence that the fungus may not be able to oversummer in Florida and most likely does not play a role as source of primary inoculum in the following seasons. This may also shed some light on other potential inoculum sources of $B$. cinerea in strawberry fields and the exact role of annual transplants as a source for primary inoculum. Our recent findings on the high frequency of nursery transplants infected with $B$. cinerea (34) support this scenario. Additionally, a high frequency of the isolates on nursery transplants was resistant to most fungicides commonly used in Florida (i.e., 15\% resistant to penthiopyrad; 34). Therefore, early management strategies in nurseries and in the fields are highly recommended to alleviate the impact of the primary inoculum early in the season.

We evaluated and substantiated the risks for resistance development to the novel generation of SDH inhibitors even before their use in the field to control $B$. cinerea. In addition to understanding the role of the multiple mutations reported in this study in resistance development to the SDHIs, future efforts should focus on developing improved rotation strategies of these fungicides with the already existing ones to extend the life of new fungicides and reduce risks for selecting for additional resistant populations.

\section{Acknowledgments}

This work was supported by a USDA-NIFA fund under project number 2010 51181-21113. We thank R. Martin and A. Zuniga, Gulf Coast Research and Education Center for technical assistance.

\section{Literature Cited}

1. Amiri, A., Brannen, P. M., and Schnabel, G. 2010. Reduced sensitivity in Monilinia fructicola field isolates from South Carolina and Georgia to respiration inhibitor fungicides. Plant Dis. 94:737-743.

2. Amiri, A., Heath, S. M., and Peres, N. A. 2012. Sensitivity of Botrytis ci- 
nerea field isolates to the novel succinate dehydrogenase inhibitors fluopyram, penthiopyrad, and fluxapyroxad. (Abstr.) Phytopathology 102:S4.4.

3. Amiri, A., Heath, S. M., and Peres, N. A. 2013. Phenotypic characterization of multifungicide resistance and in Botrytis cinerea isolates from strawberry fields in Florida. Plant Dis. 97:393-401.

4. Amiri, A., Whidden, A., and Peres, N. A. 2012. Perspective on resistance of Botrytis cinerea from strawberry to multiple fungicide in Florida. University of Florida/IFAS, Fla. Coop. Ext. Serv. Berry Veg. Times 0312-2.

5. Avenot, H. F., and Michailides, T. 2007. Resistance to boscalid fungicide in Alternaria alternata isolates from pistachio in California. Plant Dis. 91:1345-1350

6. Avenot, H. F., Sellam, A., Karaoglanidis, G., and Michailides, T. 2008. Characterization of mutations in the iron-sulphur subunit of succinate dehydrogenase correlating with boscalid resistance in Alternaria alternata from California pistachio. Phytopathology 98:736-742.

7. Avenot, H. F., Sellam, A., and Michailides, T. 2009. Characterization of mutations in the membrane-anchored subunits AaSDHC and AaSDHD of succinate dehydrogenase from Alternaria alternata isolates conferring field resistance to the fungicide boscalid. Plant Pathol. 58:1134-1143.

8. Avenot, H., Thomas, A., Gitaitis, R. D., Langston, D. B., and Stevenson K. L. 2012. Molecular characterization of boscalid- and penthiopyrad-resistant isolates of Didymella bryoniae and assessment of their sensitivity to fluopyram. Pest Manage. Sci. 68:645-651.

9. Broomfield, P. L. E., and Hargreaves, J. A. 1992. Single amino-acid change in the iron-sulfur protein sub-unit of succinate-dehydrogenase confers resistance to carboxin in Ustilago maydis. Curr. Genet. 22:117-121.

10. Culbreath, A. K., Brenneman, T. B., Kemerait, R., and Hammes, G. G. 2008. Effect of the new pyrazole carboxamide fungicide penthiopyrad on late leaf spot and stem rot of peanut. Pest Manage. Sci. 65:66-73.

11. de Miccolis Angelini, R. M., Habib, W., Rotolo, C., Pollastro, S., and Faretra, F. 2010. Selection, characterization and genetic analysis of laboratory mutants of Botryotinia fuckeliana (Botrytis cinerea) resistant to the fungicide boscalid. Eur. J. Plant Pathol. 128:185-199.

12. Fernández-Ortuño, D., Chen, F., and Schnabel, G. 2012. Resistance to pyraclostrobin and boscalid in Botrytis cinerea isolates from strawberry fields in the Carolinas. Plant Dis. 96:1198-1203.

13. Ferry, A. E., and Davis, M. 2011. Field efficacy of novel fungicides for the control of Sclerotium cepivorum in California. (Abstr.) Phytopathology 101:S52.

14. Förster, H., Kanetis, L., and Adaskaveg, J. E. 2004. Spiral gradient dilution, a rapid method for determining growth responses and $50 \%$ effective concentration values in fungus-fungicide interactions. Phytopathology 94:163170 .

15. Fought, L., Musson, G. H., and Young, H. 2011. Fluopyram fungicides for the control of disease of horticultural and row crops. (Abstr.) Phytopathology 101:S54

16. Fournier, N., Giraud, T., Albertini, C., and Brygoo, Y. 2005. Partition of the Botrytis cinerea complex in France using multiple gene genealogies. Mycologia 97:1251-1267.

17. Fraaije, B. A., Bayon, C., Atkins, S., Cools, H. J., Lucas, J. A., and Fraaije, M. W. 2012. Risk assessment studies on succinate dehydrogenase inhibitors, the new weapons in the battle to control Septoria leaf blotch in wheat. Mol. Plant. Pathol. 13:263-275.

18. Fungicide Resistance Action Committee. FRAC Code List. http://www. frac.info

19. Georgopoulos, S. G., Alexandri, E., and Chrysayi, M. 1972. Genetic evidence for the action of oxathiin and thiazole derivatives on the succinic dehydrogenase system of Ustilago maydis mitochondria. J. Bacteriol. 110:809-817.

20. Gunatilleke, I. A. U. N., Arst, H. N., and Scazzocchio, C. 1975. Three genes determine carboxin sensitivity of mitochondrial succinate oxidation in Aspergillus nidulans. Genet. Res. 26:297-305.

21. Hall, T. A. 1999. BioEdit: a user-friendly biological sequence alignment editor and analysis program for Windows 95/98/NT. Nucleic Acids. Symp. Ser. 41:95-98.

22. Hobbelen, P. J., Paveley, N. D., and Van den Bosch, F. 2010. The usefulness of mixtures of a single-site and multi-site fungicide as resistance management strategy. Phytopathology 103:690-707.

23. Ishii, H., Miyamoto, T., Ushio, S., and Kakishima, M. 2011. Lack of crossresistance to a novel succinate dehydrogenase inhibitor, fluopyram, in highly boscalid-resistant isolates of Corynespora cassiicola and Podosphaera xanthii. Pest. Manage. Sci. 67:474-482.

24. Ito, Y., Muraguchi, H., Seshime, Y., Oita, S., and Yanagi, S. 2004. Flutolanil and carboxin resistance in Coprinus cinereus conferred by a mutation in the cytochrome b (560) subunit of succinate dehydrogenase complex (Complex II). Mol. Genetics Gen. 272:328-335.

25. Kim, Y. K., and Xiao, C. L. 2010. Resistance to pyraclostrobin and boscalid in populations of Botrytis cinerea from stored apples in Washington State. Plant Dis. 94:604-612.

26. Leroux, P., Gredt, M., Leroch, M., and Walker, A. S. 2010. Exploring mechanisms of resistance to respiratory inhibitors in field strains of Botrytis ci- nerea, the causal agent of gray mold. Appl. Environ. Microbiol. 76:66156630

27. Mackenzie, S. J., and Peres, N. A. 2012. Use of leaf witness and temperature to time fungicide applications to control Botrytis fruit rot of strawberry in Florida. Plant Dis. 96:529-536.

28. Markoglou, A., and Ziogas, B. 2011. Molecular characterization of benzimidazole-resistant $B$. cinerea field isolates with reduced or enhanced sensitivity to zoxamide and diethofencarb. Pest. Biochem. Physiol. 99:118 124.

29. Matsson, M., Ackrell, B. A., Cochran, B., and Hederstedt, L. 1998. Carboxin resistance in Paracoccus denitrifians conferred by a mutation in the membrane-anchor domain of succinate:quinone reductase. Arch. Microbiol. 107:27-37.

30. Miyamoto, T., Ishii, H., Seko, T., Kobori, S., and Tomita, Y. 2009. Occurrence of Corynespora cassiicola isolates resistant to boscalid on cucumber in Ibaraki Prefecture, Japan. Plant Pathol. 58:1144-1151.

31. Miyamoto, T., Ishii, H., Stammler, G., Koch, A., Ogawara, T., Tomita, Y, Fountaine, J. M., Ushio, S., Seko, T., and Kobori, S. 2010. Distribution and molecular characterization of Corynespora cassiicola isolates resistant to boscalid. Plant Pathol. 59:873-881.

32. Monteau, S., Abouna, S., Lambert, B., and Legendre, L. 2003. Differential regulation by ambient $\mathrm{pH}$ of putative virulence factor secretion by the phytopathogenic fungus Botrytis cinerea. FEMS Microbiol. Ecol. 43:359-366.

33. Myresiotis, C. K., Karaoglanidis, G. S., and Tzavella-Klonari, K. 2007 Resistance of Botrytis cinerea isolates from vegetable crops to anilinopyrimidine, phenylpyrrole, hydroxyanilide, benzimidazole, and dicarboximide fungicides. Plant Dis. 91:407-413

34. Oliveira, S. M., Amiri, A., and Peres, N. A. 2013. The role of nursery plants as a potential source of inoculum for Botrytis cinerea and its impact on fungicide sensitivity. Phytopathology 103:S2.107.

35. Rheinheimer, J., Rieck, H., and Coqueron, P. Y. 2012. Succinate dehydrogenase inhibitors. Pages 627-687 in: Modern Crop Protection Com pounds, Vol. 1. W. Krämer, U. Schirmer, P. Jeschke, and M. Vitschel, eds. Wiley-VCH Verlag GmbH \& Co. Weinheim, Germany.

36. Scalliet, G., Bowler, J., Luksch, T., Kirchhofer-Allan, L., Steinhauer, D., Ward, K., Niklaus, M., Verras, A., Csukai, M., Daina, A., and Fonne-Pfister, R. 2012. Mutagenesis and functional studies with succinate dehydrogenase inhibitors in the wheat pathogen Mycosphaerella graminicola. PLoS One 7:e35429.

37. Shima, Y., Ito, Y., Kaneko, S., Hatabayashi, H., Watanabe, Y., Adachi, Y. and Yabe, K. 2009. Identification of three mutant loci conferring carboxinresistance and development of a novel transformation system in Aspergillus oryzae. Fungal Genet. Biol. 46:67-76.

38. Skinner, W., Bailey, A., Renwick, A., Keon, J., Gurr, S., and Hargreaves, J. 1998. A single amino-acid substitution in the iron-sulphur protein subunit of succinate dehydrogenase determines resistance to carboxin in $\mathrm{Myco}$ sphaerella graminicola. Curr. Genet. 34:393:398

39. Stammler, G., Brix, H. D., Nave, B., Gold, R., and Schoefl, U. 2008. Studies on the biological performance of boscalid and its mode of action. Pages 45-51 in: Modern Fungicides and Antifungal Compounds V. H. W. Dehne, H. B. Desing, U. Gisi, K. H. Kuck, P. E. Russel, and H. Lyr, eds. DPG-Verlag, Braunschweig, Germany.

40. Stammler, G., and Speakman, J. 2006. Microtiter method to test the sensitivity of Botrytis cinerea to boscalid. J. Phytopathol. 154:508-510.

41. Stevenson, K. L., Langston, D. B., and Sanders, F. 2008. Baseline sensitivity and evidence of resistance to boscalid in Didymella bryoniae. (Abstr.) Phytopathology 98:S151.

42. Veloukas, T., and Karaoglanidis, G. S. 2012. Biological activity of the succinate dehydrogenase inhibitor fluopyram against Botrytis cinerea and fungal baseline sensitivity. Pest Manage. Sci. 68:858-864.

43. Veloukas, T., Leroch, M., Hahn, M., and Karaoglanidis, G. S. 2011. Detection and molecular characterization of boscalid-resistant Botrytis cinerea isolates from strawberry. Plant Dis. 95:1302-1307.

44. Veloukas, T., Leroch, M., Hahn, M., and Karaoglanidis, G. S. 2013. Differential effect of SdhB gene mutations on the sensitivity to SDHI fungicides in Botrytis cinerea. Plant Dis. 97:118-122.

45. Wexler, H. M., Molitoris, E., Jashnian, F., and Finegold, S. M. 1991. Comparison of spiral gradient and conventional agar dilution for susceptibility testing of anaerobic-bacteria. Antimicrob. Agents Chemother. 35:11961202

46. Williamson, B., Tudzynsk, B., Tudzynski, P., and van Kan, J. A. L. 2007. Botrytis cinerea: the cause of grey mould disease. Mol. Plant Pathol. 8:561 580 .

47. Yanase, Y., Yoshikawa, Y., Kishi, J., and Katsuta, H. 2007. The history of complex II inhibitors and the discovery of penthiopyrad. Pages 295-303 in Pesticide Chemistry-Crop Protection, Public Health, Environmental Safety. H. Ohkawa, H. Miyagawa, and P. W. Lee, eds. Wiley-VCH, Weinheim, Germany.

48. Yin, Y. N, Kim, Y. K, and Xiao, C. L. 2011. Molecular characterization of boscalid resistance in field isolates of Botrytis cinerea from apple. Phytopathology 101:986-995 